\title{
Internas abiertas reguladas y buen funcionamiento partidario. Los casos actuales de Argentina y Uruguay
}

\section{Open primary elections with official regulation and good party functioning. The current cases of Argentina and Uruguay}

\author{
doi: http://dx.doi.org/10.32870/espiral.v25i72.6673
}

Adriana Gallo

\section{Resumen}

En este trabajo se evalúan los efectos de la aplicación del sistema de internas o primarias abiertas en Argentina y Uruguay como elemento clave de las últimas reformas políticas latinoamericanas. Se evalúa su funcionamiento en todas las elecciones en que se incorporó respecto de sus presuntos beneficios (mejorar la vida interna partidaria y ordenar al sistema de partidos), observándose que estos no se han obtenido hasta ahora, particularmente en Argentina, donde la incorporación de este mecanismo partió de principios contradictorios, sustentados en visiones antagónicas respecto de los partidos políticos que dieron lugar al establecimiento de una competencia no partidaria, personalizada o dividida en sectores. Se concluye que esto promueve la fragmentación, la inconsistencia interna y la pérdida de relevancia de los partidos políticos, tanto en lo referente a su estructura interna como a su posición y comportamiento en el marco general de las instituciones democráticas.

Palabras clave: internas abiertas y simultáneas, regulación oficial, Argentina, Uruguay, partidos políticos.

\section{Abstract}

This paper evaluates the effects of the open primary elections system at Argentina and Uruguay as a key element during the last Latinamerican political reforms. The presumed benefits of this practice are considered -improving internal party life and ordering the party system, evaluating its functioning in all the elections since its incorporation and comparing the results to ascertain the evolution of its implementation. We note that these benefits have not been obtained so far, particularly in Argentina, where the incorporation of this mechanism was based on contradictory principles with antagonistic points of view about political parties which only hinders a rightful appraisal of them. All this rises the establishment of a kind of competition that is not party-ruled, personalized or divided into sectors, which ends up promoting fragmentation, internal inconsistencies and loss of relevance of the political parties, both in terms of their internal structure as well as their position and behaviour within the general overview of democratic institutions.

Keywords: Simultaneous open primaries, official regulation, Argentina, Uruguay, political parties.

-Investigadora miembro del Observatorio Electoral Latinoamericano (OBLAT), e Investigadora Adjunta del CONICET, Argentina. ORCID: http://orcid.org/0000-000I-7885-4768

doctoraag75@hotmail.com

Fecha de recepción:07 de abril de 2017. Fecha de aceptación:2I de noviembre de 2017. 


\section{Introducción}

En este trabajo, se realiza un estudio acerca del mecanismo electoral de primarias o internas abiertas presidenciales, el cual supone que la nominación de candidaturas partidarias sea realizada mediante una elección en la que se autorice a participar a todo ciudadano empadronado en el registro electoral nacional del país (Gallagher y Marsh, 1988; Freidenberg, 2003). Este método, que formó parte de las agendas de reformas político-institucionales de las últimas décadas en América Latina, estaba teóricamente destinado a mejorar el funcionamiento partidario y ordenar el sistema de partidos (Colomer, 2000; Alcántara Sáez, 2002; Alcántara Sáez y Freidenberg, 2003; Muñoz, 2003; Carey y Polga Hecimovich, 2004; Gallo, 2011).

El presente trabajo se concentra en los casos de Argentina y de Uruguay, los únicos dos países del continente en los cuales este mecanismo de selección ha sido incorporado formalmente en sus legislaciones nacionales. ${ }^{1}$

En Argentina, con la sanción de la Ley 26.571, en 2009, se formalizó el método de primarias abiertas simultáneas y obligatorias (PASO) para los cargos de elección popular nacional, siendo estas organizadas, controladas y tuteladas por el organismo electoral nacional del país.

La reforma de la legislación electoral argentina tuvo su manifiesta inspiración en la normativa vigente en Uruguay. ${ }^{2}$ La enmienda en la ley argentina fue propuesta por la coalición gubernamental en un momento en el que el oficialismo perdía aliados y declinaba en popularidad. En efecto, el

I. Si bien en la mayoría de los países latinoamericanos las primarias han sido utilizadas de forma unilateral por alguna de las fuerzas partidarias, en casi ninguno de ellos rigen disposiciones formales que impongan su realización. Estas sólo existen en Honduras, Panamá y Paraguay (aunque en ellos son cerradas para los afiliados o miembros partidarios) (Gallo, 2017; Zelaznik, 20I5).

2. Se recomienda al lector buscar en la prensa argentina un discurso dado por la presidenta Cristina Fernández el 15 de agosto de $20 \mathrm{II}$. 
Gobierno kirchnerista había impulsado esta reforma para que, por un lado, introdujera fluidez al juego político y, por otro lado, disminuyera la capacidad operativa de sus rivales (Caruncho, 2014; Gallo, 2017).

Por su parte, en Uruguay, el sistema de internas abiertas surgió a mediados de los noventa. Ante la alteración sufrida en el sistema partidario, ${ }^{3}$ las fuerzas políticas tradicionales-que habían ido adoptando progresivamente posiciones derechistas (Altman, 2004) - se coligaron con el objetivo de frenar el crecimiento del Frente Amplio (FA), dando paso a la reforma constitucional de 1996 (Lanzaro, 2001), en la que se sustituyó a la Ley de Lemas y se puso en práctica un sistema de tres fases para los comicios presidenciales (internas abiertas, elecciones generales y balotaje o segunda vuelta electoral). ${ }^{4}$

Ahora bien, en esta investigación, primero, se consideran los argumentos que han respaldado la incorporación de este mecanismo, ${ }^{5}$ según los cuales la utilización de primarias abiertas conduciría al perfeccionamiento de las prácticas partidarias, tanto en lo interno (considerando al partido como una organización voluntaria que busca colocar a sus dirigentes en puestos de poder) como en lo externo (como parte de un sistema partidario en el que el partido entra

3. En las últimas elecciones, prácticamente se había establecido un triple empate: el Partido Colorado (PC) obtuvo en su conjunto el $32.35 \%$ de los votos, el Partido Nacional (PN) el $31.21 \%$, y el Frente Amplio (FA) el 30.61\%.

4. Cabe mencionar que el hecho de que este dispositivo electoral trifásico haya estado precedido por la Ley de Lemas, y de que en él se reflejara todo el arco de opciones -partidarias y subpartidarias- ante los ciudadanos, permitió a los partidos mantener una supremacía por sobre las fracciones internas sin perder relevancia como canales de mediación política. Estas características previas posibilitaron que en Uruguay la transición de un sistema a otro sucediera de un modo relativamente armónico y natural (Gallo, 20I I).

5. Particularmente en Argentina, en la medida en que allí este sistema constituyó una de las piezas clave de la Ley 26.57I, mientras que en Uruguay formó parte de una reforma constitucional que abarcó múltiples temas de carácter trascendente. 
en competencia con otros congéneres) ${ }^{6}$ (Alcántara Sáez y Freidenberg, 2003), realizando una revisión de la literatura sobre esta temática a nivel internacional.

Luego, se abordan comparativamente los casos de Argentina y de Uruguay considerando todas las oportunidades en las que se utilizó dicho método electoral, teniendo en cuenta las diferencias existentes originariamente en los sistemas partidarios de cada uno de los países y las particularidades distintivas que adoptó la legislación electoral en cada caso. Si bien son escasas las situaciones analizadas, se sostiene provisoriamente que hasta el momento no ha habido una correlación positiva entre el empleo de este método selectivo y el cumplimiento de los beneficios esperados.

\section{Sistema de internas o PASO. Discusión teórica e hipótesis}

En este apartado, se consideran los argumentos teóricos esbozados por los impulsores académicos del sistema de primarias/internas abiertas, muchos de los cuales fueron utilizados y expuestos públicamente por sus impulsores políticos.

Uno de los principales objetivos buscados con este sistema es que los ciudadanos comunes cuenten con la posibilidad de seleccionar a sus opciones favoritas dentro de los partidos con los cuales simpatizan (Tejerizo, 2009; Tullio, 2010). En efecto, se busca que los individuos participen en dicho evento selectivo para emitir un voto sincero señalando, dentro de su partido predilecto, a su candidato favorito en términos ideológicos, posicionales o particulares (Gallo, 2011), lo que

6. Según el director de la Dirección Nacional Electoral, Alejandro Tullio (20 I I), esta reforma reconocía la centralidad de los partidos políticos y procuraba garantizar la salud del sistema partidario. Así, se buscaba mejorar a los partidos en su calidad de representantes del pueblo, revalorizando los valores, ideas y principios, y relegitimando el origen y composición de la oferta electoral. 
constituye un mecanismo democrático de nominación de candidatos (Zovatto, 2001; Alcántara Sáez, 2002).

Los defensores del sistema argumentan que los candidatos seleccionados mediante primarias gozan de mayor legitimidad de origen que aquellos designados por un grupo partidario reducido o elegidos a dedo por los líderes partidarios (Freidenberg, 2003; Passarello Luna, 2009; Straface y Page, 2010). A su vez, se sostiene que la existencia de primarias competidas presenta ciertas ventajas respecto de la nominación de candidaturas por consenso o acuerdo partidario (Ansolabehere, Snyder y Stewart, 2000; Carey y Polga Hecimovich, 2004; Kemahlioglu, Weitz-Shapiro e Hirano, 2009).

Paralelamente, se argumenta que la existencia de una fase electoral preliminar como las primarias o internas permite que los electores tengan noción respecto de cómo están distribuidas las preferencias de los otros votantes y de la probabilidad de triunfo de las alternativas en competencia (Tullio, 2010), produciéndose una clarificación respecto de las expectativas de viabilidad de los contendientes calificados (Reynoso, 2015). Así, la existencia de una instancia electoral inicial puede promover lo que se denomina un efecto batacazo (Gallo, 2017), lo cual, a su vez, otorgaría un importante impulso legitimador al ganador de la contienda (Passarello Luna, 2009).

El batacazo se refiere a la inesperada performance positiva de un partido/sector/candidato -que generalmente constituye la novedad o revelación- en las primarias, que provoca una reconfiguración de expectativas a su favor. El batacazo, a su vez, puede ser interno (si se impone un sector o precandidato inesperado) o general (si dentro del conjunto de partidos, hay uno que resulta sorpresivamente favorecido). El efecto batacazo es entonces la réplica de esa tendencia ascendente en la instancia siguiente, lo que implicaría que en las primarias tuvo lugar el impacto legitimador 
hacia un candidato. ${ }^{7}$ En suma, se presume que una buena performance en la primera fase electoral permitiría al partido crecer electoralmente en las instancias subsiguientes.

Por otro lado, se aduce que un sistema de primarias con regulación oficial, al operar como fase de preselección, tiende a fomentar el ordenamiento de la oferta partidaria (Tejerizo, 2009; Tullio, 2010). Como se sabe, las reglas electorales provocan efectos mecánicos, afectando el número y actores que forman parte del sistema (Cox, 1997), y también efectos psicológicos, que remiten a las estrategias de élites políticas y votantes para adaptarse a los límites mecánicos del sistema electoral (Benoit, 2006; Zelaznik, 2015). En ese sentido, el establecimiento de pisos para acceder a la elección general tenía como objeto, por un lado, reducir el número de agrupaciones que competían (Escolar, 2011), mitigando la dispersión existente, y, por otro, promover la unidad entre partidos similares, a través de la agregación de ciertas demandas e intereses comunes (Passarello Luna, 2009; Tejerizo, 2009). Según se ha argumentado, todo esto impulsaría el ordenamiento de la dinámica partidaria, facilitando la presencia de organizaciones fuertes, duraderas y con significativo anclaje social (Tullio, 2010).

En definitiva, el mecanismo de primarias abiertas es un sistema peculiar de votación, estipulado para seleccionar al candidato único y oficial del partido o coalición partidaria ${ }^{8}$ (Colomer, 2004, p. 96). Así, en tanto que el partido (o coalición de partidos) constituye la unidad de competencia político-electoral, se presupone que el criterio partidario

7. Esto sería algo similar a lo que ocurre en Estados Unidos (EUA), donde las primarias se dan a través de varios meses, proveyendo un efecto-demostración al resultado final (Colomer, 2000). Como allí las candidaturas presidenciales se hacen y deshacen con gran rapidez (Bartels, 1988), en la etapa previa a la entrada estratégica suele haber muchos casos de candidatos tapados (Colomer, 2000). 8. Eso figura en la legislación argentina (artículo 44, capítulo VII). Además, el partido por ley ostenta el monopolio de la postulación de candidaturas a cargos electivos (artículo 38 constitucional). 
es la principal variable que los ciudadanos consideran a la hora de configurar sus preferencias políticas y decidir su $\operatorname{voto}^{9}$ (Gallo, 2017).

Sin embargo, en Argentina la mayor parte de los votantes no suelen utilizar el criterio partidario para elaborar sus preferencias $^{10}$ (Passarello Luna, 2009), sino que se guían por cuestiones de corto plazo, como el apoyo o no a la gestión vigente, traducido en el eje Gobierno-oposición (Jones y Hwang, 2007; Clérici, 2013; El Estadista, 2015), junto a elementos subjetivos y personales de los candidatos (Tullio, 2010; 2015; iProfesional, 2015; Gallo, 2017).

A la inversa, en sistemas de partidos estructurados como el de Uruguay -donde además, existe una porción importante de la población que milita, se adhiere o simpatiza firmemente con alguna de las fuerzas partidarias existentes (González, 1999; Bottinelli, 2009; Moreira, citado en Caillabet, 2014)-, existe habitualmente una superposición entre los factores partidarios y los ideológicos: cuanta más consistencia haya entre el aspecto partidario y el ideológico, mayor será la eficacia de los partidos como procesadores de información política a la hora de orientar el voto ciudadano (Anduiza y Bosch, 2004), lo cual constituiría una condición de posibilidad para que el sistema de primarias permitiera la selección de candidatos a través del pronunciamiento ciudadano sobre la base del criterio partidario.

Ahora bien, la pregunta de investigación que guía el presente trabajo es: ¿con el sistema de internas o primarias abiertas se tiende a mejorar el funcionamiento partidario, ya sea en lo interno (fortaleciendo al partido como organi-

9. Esto es consistente con lo concluido en los estudios sobre comportamiento electoral que consideran que la simpatía partidista, junto con la ideología, constituyen los principales atajos informativos útiles para orientar las preferencias políticas de los individuos (Cox, 1997; Anduiza y Bosch, 2004).

10. Sucede que una importante porción de los ciudadanos independientes experimenta rechazo hacia la política y es refractaria a alguna de las fuerzas políticas existentes (Gallo, 20I7). 
zación voluntaria de miembros, sin mella de su unidad y consistencia interna $)^{11}$ o en lo externo (mejorando al partido como pieza integrante de un subsistema más amplio del que forma parte) $?^{12}$

A su vez, la hipótesis del presente trabajo es que con la aplicación del sistema de internas o primarias abiertas no suelen lograrse los objetivos buscados por los promotores teóricos del mismo, relativos al mejoramiento del funcionamiento partidario, ni en lo interno ni en lo externo. Esto tiende a pronunciarse cuando los partidos son débiles y los ciudadanos no se sienten identificados con ellos (particularmente, si la legislación no adopta cláusulas específicas para contrarrestar estas tendencias).

De este modo, se busca analizar el funcionamiento del mecanismo de elecciones internas abiertas comparando dos casos en los que se adoptó una normativa parecida, aunque en situaciones políticas desemejantes, para luego ser aplicada a organizaciones partidarias con caracteres diferenciales en Argentina y Uruguay. Se procura evaluar el ajuste o desajuste entre los objetivos teóricos de los impulsores del sistema y las consecuencias obtenidas, subrayando las posibles alternativas que pueden hallarse en función del contexto institucional y partidario en cuestión.

\section{Las primarias/internas abiertas. El estudio de los casos}

La Tabla 1 señala cuestiones normativas formales del sistema de primarias/internas abiertas. Posteriormente, se detallan casos concretos de aplicación del mecanismo.

II. Esto implica que cada partido despierte una adhesión ciudadana importante que se pronuncie sinceramente por alguno de los candidatos con oportunidad, sin que haya conflictividad entre ellos durante la contienda.

12. Esto supone que los votantes de cada una de las organizaciones partidarias no migren a otras fuerzas luego del proceso electivo, acrecentando la votación originaria.

\section{4}


Tabla 1. Cuestiones normativas formales de las primarias / internas abiertas en Argentina y Uruguay

\begin{tabular}{|c|c|c|}
\hline Características & Argentina & Uruguay \\
\hline $\begin{array}{l}\text { Obligatoriedad de la } \\
\text { postulación para partidos }\end{array}$ & Sí & Sí \\
\hline $\begin{array}{l}\text { Obligatoriedad del voto } \\
\text { para ciudadanos }\end{array}$ & Sí & No \\
\hline $\begin{array}{l}\text { Carácter vinculante } \\
\text { de esta etapa }\end{array}$ & Sí & Sí \\
\hline $\begin{array}{l}\text { Carácter eliminatorio } \\
\text { de esta etapa }\end{array}$ & Sí & Sí \\
\hline $\begin{array}{l}\text { Piso para pasar } \\
\text { a la elección general }\end{array}$ & $\begin{array}{l}\text { 1.5\% de los votos } \\
\text { válidamente emitidos } \\
\text { del distrito }\end{array}$ & 500 votos* \\
\hline Situación de perdedores & $\begin{array}{l}\text { Impedidos de } \\
\text { integrar fórmula }\end{array}$ & $\begin{array}{l}\text { Posibilidad de } \\
\text { acuerdos e inclusión }\end{array}$ \\
\hline ¿Qué categorías se votan? & $\begin{array}{l}\text { Fórmula presidencial } \\
\text { completa y todos } \\
\text { los legislativos } \\
\text { nacionales (por } \\
\text { separado) }\end{array}$ & $\begin{array}{l}\text { Sólo el postulante } \\
\text { que encabeza el } \\
\text { binomio presidencial }\end{array}$ \\
\hline $\begin{array}{l}\text { Condición para presentar } \\
\text { precandidaturas }\end{array}$ & $\begin{array}{l}\text { Aval de adherentes } \\
\text { correspondientes } \\
\text { al } 0.1 \% \text { de los } \\
\text { empadronados a nivel } \\
\text { nacional }\end{array}$ & $\begin{array}{l}\text { Según carta orgánica } \\
\text { partidaria }\end{array}$ \\
\hline $\begin{array}{l}\text { Consagración del } \\
\text { candidato }\end{array}$ & $\begin{array}{l}\text { Directamente y a } \\
\text { pluralidad simple }\end{array}$ & $\begin{array}{l}\text { Directamente, con } \\
\text { mayoría especial, o } \\
\text { indirectamente (por } \\
\text { miembros partidarios } \\
\text { en caso de no } \\
\text { lograrse tal mayoría) }\end{array}$ \\
\hline
\end{tabular}

*Es la misma cantidad de votos que se requieren legalmente para conformar un partido político y para conservar su personería jurídicopolítica, mientras que en Argentina para esto último se requiere 4\% de afiliados permanentes.

$\overline{\text { Fuente: elaboración propia con base en las constituciones nacionales y }}$ las normativas electorales de la República Argentina y de la República Oriental del Uruguay. 
Las características diferenciales de ambas legislaciones son, en detalle:

- Participación obligatoria u opcional. En Uruguay, las internas abiertas constituyen eventos de naturaleza optativa para los ciudadanos independientes, mientras que en Argentina se obliga a todos los ciudadanos empadronados a participar en ellas (artículo 19, capítulo I). En este último caso, la compulsividad de la asistencia se dispuso en orden de obtener una injerencia principal de los independientes, quienes constituyen la gran mayoría del universo total de electores ${ }^{13}$ (Haro, 2002), y lograr, con ello, la selección de los postulantes más acordes con las preferencias de la ciudadanía común (Harmel y Janda, 1982; Gallagher y Marsh, 1988). Sin embargo, la obligatoriedad de la intervención ciudadana en un evento relativo a las competencias internas del partido político implica una intromisión externa sobre la vida partidaria ${ }^{14}$ (Prats, 2012), y entra en contradicción con la naturaleza propia de los partidos, los cuales, por definición, son asociaciones voluntarias, orientadas a un sector específico del electorado, cuya adscripción no puede lograrse por medios coercitivos (Weber, 1922).

- Umbral legal. El piso que la ley argentina impone a los partidos para poder superar las PASO es altamente restrictivo (más de cincuenta veces más alto que el uruguayo). Corresponde mencionar aquí que con esta cláusula se habría buscado dejar fuera de juego a competidores externos (particularmente a aquellos ubicados a la izquierda del Gobierno kirchnerista),${ }^{15}$ lo cual

13. En Argentina, siete de cada diez ciudadanos se consideran independientes (iProfesional, 2015).

14. Esto difiere de lo ocurrido en otras partes del mundo, en las cuales las modificaciones en los procedimientos de selección de candidatos han provenido de una decisión interna de los partidos (Kemahlioglu,Weitz-Shapiro e Hijaro, 2009). 15. En las últimas elecciones, ninguna de las fuerzas de izquierda revolucionaria había logrado ese porcentaje. 
favorecía las oportunidades de que el oficialismo pudiera posteriormente aglutinar al amplio sector del electorado refractario a la derecha (Gallo, 2017).

- Situación en la que quedan los perdedores de la contienda interna. En Argentina, en las PASO compiten fórmulas partidarias completas (artículo 6). Esta situación no genera mecanismos consensuales ni crea espacios para las minorías internas. A la inversa, al darle lugar solamente a los que obtienen el primer puesto, la contienda se plantea como una lucha de suma cero, lo cual desincentiva la competencia interna en tanto no genera elementos compensatorios ni provee beneficios subalternos para los que resulten derrotados en las PASO (Gallo, 2017). En Uruguay, en cambio, se puede incluir a un precandidato derrotado de las primarias como compañero en la fórmula presidencial. Esto permite darle un lugar dentro de la unidad superior (partido/ coalición) a un sector gravitante que haya sido expelido en las internas, reteniendo a sus seguidores y potenciales votantes (Buquet y Piñeiro, 2014). Este elemento estimula la competitividad (Buquet y Piñeiro, 2011) y acrecienta los incentivos para establecer compromisos intrapartidarios. ${ }^{16}$

- Categorías que se eligen. Vinculado directamente con lo anterior, en Uruguay se elige sólo al candidato a la presidencia y, a partir de allí, se designan los lugares a ser ocupados por aquellos que tomaron parte en cada contienda. En Argentina, la cláusula que impone la elección de la fórmula completa e inamovible tenía el objeto de evitar que los miembros del binomio presiden-

16. Las internas resueltas de modo más satisfactorio fueron las que incluyeron al segundo lugar como vicepresidente (Buquet y Piñeiro, 20I I): la interna del PC en 1999, y las del PN y el FA en 2009. 
cial tuvieran un color político distinto ${ }^{17}$ (Gallo, 2011). La imposición de una sutura legal entre los sectores que compiten, y que podrían conformar una misma fórmula, parte de la presunción de que la entidad (coalición/ partido) que los engloba es tan lábil y heterogénea que no es posible asegurar la perduración de los acuerdos más básicos durante el periodo gubernamental. Esto último está en consonancia con el carácter transitorio que la legislación le otorga a la alianza electoral ${ }^{18}$ (Clérici, 2013, p. 12). En efecto, la ley argentina incita a la construcción de coaliciones estrictamente electoralistas, establecidas como opción de ultima ratio para las fuerzas cuya propia supervivencia esté en peligro, o bien, como respuesta a la necesidad de coordinación de ciertas fuerzas contra un sector caracterizado como mal mayor ${ }^{19}$ (Tullio, 2015).

- Presentación de precandidaturas. En Uruguay, la postulación interna no depende sólo de una decisión unilateral del aspirante presidencial, sino que este debe contar con la anuencia de algún sector interno orgánicamente constituido, cuyo sello pretenda utilizar en la elección primaria. En Argentina, en cambio, las laxas condiciones para la postulación promueven que la viabilidad del postulante sea medida en función de su apoyo personal en la opinión pública, lo cual estimula la presencia de líderes de popularidad (Cheresky, 1999), quienes van decidiendo circunstancialmente el vehículo partidario

17. Esto a raíz de la experiencia fracasada de la Concertación Plural-una coalición entre el Frente para la Victoria (FPV) y los llamados radicales $K$, que apoyaban al kirchnerismo-, en 2007, la cual eclosionó precisamente cuando el vicepresidente Julio Cobos -un radical K- votó en contra de una importante iniciativa oficialista. 18. Según lo estipulado por la ley, las alianzas son agrupaciones políticas de carácter transitorio, constituidas con el único efecto de participar en elecciones, postulando candidatos para cargos públicos (artículo 6).

19. Como los acuerdos pluripartidistas se realizan en un momento en el que no se sabe cómo va a salir el candidato en las PASO, se torna incierta la viabilidad y permanencia de los mismos de cara a las instancias subsiguientes. 
para competir. Esto se agrava con la elección interna a pluralidad simple, que existe en Argentina (Zelaznik, 2015) y que también diferencia a ambos sistemas.

En suma, estos elementos permiten dar cuenta de que, pese a que los impulsores políticos de la reforma en Argentina adujeron teóricamente argumentos semejantes a los esbozados por los impulsores académicos del sistema de primarias, la lectura minuciosa de la ley permite revelar la existencia de cláusulas y elementos que contradicen y obstaculizan la consecución de los beneficios perseguidos en abstracto (que ya, de por sí, como veremos luego, son difíciles de alcanzar aun en condiciones favorables, que podrían ilustrarse mediante el caso uruguayo).

\section{I. Estudio de los casos}

Veamos ahora cómo sucedió la aplicación de este sistema en ambos países, teniendo en cuenta las características previas de los partidos y sistemas partidarios en cada uno.

\section{I. I. Uruguay}

En Uruguay, luego de un siglo de bipartidismo y una década de tripartidismo, a partir de 2004 el sistema político se estabilizó en dos bloques o familias partidarias: el bloque desafiante y el tradicional (Piñeiro, 2014), que agrupaban a sectores definidos de acuerdo con el criterio partidario (FA, por un lado, y PC y PN por otro) y con el ideológico (centroizquierda-centroderecha). A partir de entonces, ambos bloques coincidieron con dos grandes áreas: una de Gobierno y otra de oposición (Bottinelli, 2009; Buquet y Piñeiro, 2011). A su vez, los partidos uruguayos, pese a ser internamente fraccionados, son sólidos y estables (Yaffé, 2005), lo que permite que los votantes puedan trazar una adecuada topografía de lo que representa cada uno de ellos. 
En este país, las elecciones internas abiertas simultáneas y obligatorias suceden desde que el sistema electoral fue modificado en 1996. En todas las oportunidades, al menos dos de los partidos principales presentaron competencia, aunque no todas las internas fueron competitivas. En 1999, el FA postuló al líder indiscutido Tabaré Vázquez junto a la candidatura testimonial de Danilo Astori; en el PC, Jorge Batlle compitió contra Luis Hierro, a quien terminó ganándole; y en el PN, Luis Alberto Lacalle Herrera derrotó a los desafiantes Juan Andrés Ramírez y Alberto Volonté (Buquet y Chasquetti, 2005).

En 2004, en el FA también compitió Vázquez como único candidato, pero apoyado por diferentes listas internas. En el PC se presentó Guillermo Stirling, como principal candidato, junto a otros contendientes menores sin oportunidades. En el PN, compitieron Lacalle y Jorge Larrañaga, quien resultó ganador (Bottinelli, 2009).

En 2009, en el FA, José Mujica y Danilo Astori se midieron en unas internas tensas y conflictivas (Cardarello y Yaffe, 2011). En esa instancia, contra la mayoría de los pronósticos, el FA obtuvo menor porcentaje que el PN, y el ganador Mujica resultó menos votado individualmente que Lacalle Herrera (quien, a su vez, derrotó a su contrincante Larrañaga). En consecuencia, el PN y su postulante emergieron públicamente como los grandes triunfadores de la jornada (Cardarello y Yaffe, 2011).

En 2014, en el FA Tabaré Vázquez compitió contra la desafiante sin oportunidades Constanza Moreira. En el PC, se postuló Pedro Bordaberry contra José Amorín, y en el PN Luis Lacalle Pou (hijo de Lacalle Herrera) compitió contra el candidato favorito y jefe partidario, Jorge Larrañaga. Finalmente, dentro del FA y del PC se impusieron los candidatos esperados, Vázquez y Bordaberry, respectivamente. En la interna del PN, sorpresivamente Lacalle Pou derrotó 
a Larrañaga, ${ }^{20}$ ejerciendo un claro liderazgo de popularidad -que posteriormente demostró ser efímero-, que aglutinaría a la oposición.

Una vez superadas las internas, de cara a la elección general, las encuestas preveían una diferencia de diez puntos o menos entre Vázquez y Lacalle Pou, ${ }^{21}$ que derivaría en un escenario abierto para el balotaje. Sin embargo, los resultados de la primera vuelta divergieron respecto de tales pronósticos, ${ }^{22}$ denotando que el área de atracción gubernamental era más apoyada que todo el polo opositor sumado. A la vez, en la medida en que no se produjo el efecto batacazo que podía presagiarse luego del resultado interno, Lacalle Pou terminó golpeado, al no haber alcanzado las expectativas previstas. Finalmente, en el balotaje se impuso Vázquez (56.62\% a $43.38 \%$ de los votos). ${ }^{23}$

Esta última elección presidencial tuvo como elementos significativos, por un lado, el destacado predominio del voto económico ${ }^{24} \mathrm{y}$, por otro, la alteración en la composición del voto del FA, el cual sufrió deserciones por la izquierda ${ }^{25} \mathrm{y}$ paralelamente recibió el apoyo de votantes que se fugaban

20. Las encuestas hablaban de una interna reñida, pero todas coincidían en que estaba encabezada por Larrañaga (CIFRA, 20 I4; Factum, 20 I4; Equipos Mori, 20I4). Con el triunfo interno de Lacalle Pou, la intención de voto hacia el PN creció aproximadamente cinco puntos, considerando las encuestas de CIFRA, Factum, Equipos Mori y Radar.

21. Cinco de las principales encuestadoras del país (CIFRA, Factum, Equipos Mori, Interconsult y Opción) ubicaban a estas fuerzas aproximadamente con 40\% y $30 \%$ de las preferencias, respectivamente (Núñez Castellano, 20I4).

22. El PN obtuvo el $30.9 \%$ y el FA el $47.8 \%$ de los votos, consiguiendo también la mayoría parlamentaria (ver: http://www.corteelectoral.gub.uy/gxpsites/).

23. En esta elección interna, tuvo lugar la votación más baja del FA desde su fundación hasta la actualidad, así como la consagración de un presidente uruguayo -Tabaré Vázquez- electo con mayor porcentaje de voto popular (en el balotaje). 24. Un $48 \%$ de los votantes del FA adujo que lo había elegido dados los buenos Gobiernos de esta coalición, y el $44 \%$ dijo hacerlo por la mejora económica de los últimos años (Interconsult, 2014).

25. Los votos acaparados por las fuerzas restantes, exceptuando al PC, corresponderían a disconformes con el Gobierno del FA. Este fenómeno no se había advertido en 2009, momento en el cual Mujica había reavivado la esperanza de un giro a la izquierda, asfixiando la propuesta de la izquierda radical (Garcé, 2010, p. 5 I8). 
del bloque fundacional/tradicional (Garcé, 2014), compensando aquel efecto. Efectivamente, a medida que el FA se fue estabilizando en el poder, dejando de ser una fuerza de resistencia para configurarse en una coalición de Gobierno, fue perdiendo algunos de sus seguidores fieles originarios, más radicalizados (Bottinelli, 2014; Garcé, 2014), y ganando electores más estratégicos y moderados (Moreira, citado en Caillabet, 2014).

\section{I. 2. Argentina}

Desde 2001 y 2002, el escenario político argentino ha estado compuesto por múltiples fuerzas partidarias lábiles y poco institucionalizadas, que han sufrido el desmembramiento de sectores internos (los cuales han pasado del Gobierno a la oposición, y viceversa) y han exhibido tanto inconsistencias de tipo ideológico y programático (Passarello Luna, 2009) como incongruencias a nivel territorial (Clérici, 2013).

Con la finalidad de hacer frente a esa situación, fue establecida la Ley de Democratización de la Representación Política, la Transparencia y la Equidad Electoral (Ley 26.571), mediante la cual se instauró el sistema de primarias abiertas simultáneas y obligatorias.

En el primer proceso eleccionario en el que se aplicaron las PASO (año 2011), el Frente para la Victoria (FPV), partido de Gobierno, postuló a la mandataria Cristina Kirchner como candidata única, en un escenario político en el que su triunfo final aparecía como cuasiasegurado. Ante esa situación, los partidos opositores también presentaron listas unitarias, para evitar potenciar su fragmentación (Gallo, 2017). En ese momento, la presencia excluyente de la mandataria en funciones ocasionó que prevaleciera el eje Gobierno-oposición (Kollman, 2011).

Las PASO se volvieron a implementar para los comicios legislativos de medio término, en 2013, en un momento en el 
que se perfilaba el agotamiento del ciclo kirchnerista (Gallo y Bartoletti, 2013), y luego para las elecciones presidenciales de 2015, ocasión en la cual el eje Gobierno-oposición se volvió mucho más fluido de lo que había sido cuatro años atrás (El Estadista, 2015). En este proceso electoral, que era de alternancia presidencial dado el agotamiento de los mandatos consecutivos de la presidenta Kirchner, aparecían tres candidatos con oportunidades: el oficialista Daniel Scioli (del FPV), quien no estaba claramente identificado con el kirchnerismo, y los opositores Mauricio Macri (del partido Propuesta Republicana-PRO-), jefe de Gobierno de Buenos Aires, y Sergio Massa (del Frente Renovador). Mientras que el primero se postuló como candidato único de la coalición oficialista FPV (que mantuvo su denominación y sello), los otros dos postulantes constituyeron sendas coaliciones ad hoc, personalistas y heterogéneas (Cambiemos ${ }^{26}$ y UNA, ${ }^{27}$ respectivamente), y presentaron una competencia interna testimonial.

En las PASO de agosto, el FPV (sin competencia) salió en primer lugar, ${ }^{28}$ y Cambiemos obtuvo en segundo (con el previsible triunfo interno de Macri), ${ }^{29}$ estableciendo una polaridad más nítida entre el par Gobierno-oposición. A partir de allí, en la elección general, se auguraba una amplia

26. Frente constituido ad hoc y encabezado por el PRO, al cual se anexaron la Coalición Cívica (CC) y la Unión Cívica Radical (UCR), con el fin de respaldar la postulación de Macri (El Estadista, 2015), en tanto exponente más viable y competitivo de la oposición al kirchnerismo (Gallo, 2017).

27. Frente coyuntural compuesto por el Frente Renovador (FR), liderado por Massa, y la Unión por Córdoba (UPC), sector encabezado por el peronista opositor cordobés José Manuel de la Sota.

28. Con el $38.67 \%$ del apoyo, cerca de lo necesario para ganar sin balotaje. El sistema es de mayoría calificada (45\%), con umbral rebajado (40\%) y distancia de diez puntos (según el artículo 98 de la constitución argentina).

29. En la primaria, Cambiemos sacó el $30.11 \%$ de los votos. Internamente, Macri obtuvo el $81.33 \%$ de los votos, Sánz (UCR) el I I.10\%, y Carrió (de la CC) sólo el 7.57\% (ver: http://www.elecciones.gob.ar/). 
diferencia de Scioli sobre Macri, ${ }^{30}$ pero, sorpresivamente, los dos contendientes estuvieron mucho más cerca de lo previsto (37.08\% y $34.15 \%$, respectivamente). Finalmente, en el balotaje, triunfó el postulante de Cambiemos, haciéndose acreedor de un amplio y difuso -programática e ideológicamente- consenso opositor al kirchnerismo ${ }^{31}$ (Gallo, 2017).

\section{2. Comparación entre los casos}

A continuación, se expone sintéticamente cómo se sucedieron todas las internas/primarias abiertas en cada uno de los dos países revisados, considerando la discusión sobre la temática anteriormente desarrollada. Se tienen en cuenta las condiciones para lograr los objetivos teóricos de este sistema electoral, relativos al mejoramiento del funcionamiento partidario, tanto en lo interno como en lo externo, las cuales fueron mencionadas previamente y consideradas como variables de análisis en la hipótesis de trabajo.

A partir de los valores obtenidos en cada una de las condiciones revisadas, determinaremos si en cada caso se ha producido o no un adecuado cumplimiento de los requisitos postulados para lograr los propósitos buscados con este mecanismo de selección de candidatos. Con esta finalidad, se medirán:

- Nivel de participación ciudadana en la interna. Se establecerá qué concurrencia ha habido por parte de los electores habilitados en cada elección primaria y cómo se ha distribuido esta entre las diversas fuerzas políticas que se postulaban, buscando constatar la congruencia

30. Las encuestas ubicaban a Scioli muy por encima de Macri, considerando como una opción la definición en primera vuelta (ver:http://observatorio.lapoliticaonline. com/\#pv; http://www.perfil.com/politica/Scioli-ganaria-en-primera-vuelta-vence-aMacri-en-ballottage-pero-no-a-Massa-20151017-0163.html).

31. Según un informe del Observatorio Electoral Argentino (2015), Macri se nutrió de un $52 \%$ del voto de Massa, del 54\% del peronismo disidente, del $28 \%$ de la centroizquierda, del $2 \%$ de la izquierda y del 17\% de los que habían votado previamente blanco o nulo.

\section{4}


entre el selectorado interno -es decir, el electorado que selecciona en primarias (Rahat y Hazan, 2001) - y el electorado general (Page, 2016). A la vez, se evaluará el posible voto sincero -es decir, el porcentaje de apoyo recibido por cada fuerza política en la primaria, sobre el total del padrón electoral- ${ }^{32}$ y se determinará si este ha tendido o no a concentrarse en el candidato ganador (lo que posibilitaría la gestación de un consenso positivo a su favor).

- Nivel de competencia y competitividad. Se evaluará si en la primaria de cada partido se presentaron al menos dos precandidatos competitivos y diferenciados. Se establecerá la existencia de competitividad si la diferencia entre los dos primeros contendientes es inferior a los quince puntos porcentuales (Buquet y Piñeiro, 2011). De todos modos, cabe señalar que cuando hay competitividad interna, se corre el riesgo de que los seguidores de los candidatos derrotados se orienten hacia otras fuerzas en la elección general (Epstein, 1980; Denver y Hands, 1985; Boix, 1998; Atkenson, 1998; Colomer, 2000; Piñeiro, 2014), con lo cual la competitividad en sí misma no garantiza necesariamente efectos positivos sobre el funcionamiento partidario.

- Moderación. Es más factible que se eviten defecciones de los perdedores si las primarias son moderadas que si transcurren de un modo conflictivo (Piñeiro, 2014; Malamud, 2015; Zelaznik, 2015), ${ }^{33}$ lo que a su vez

32. El nivel de sinceridad en la adhesión varía en función de que las primarias sean compulsivas o voluntarias. En estas últimas, puede llegar a revelarse qué partido/sector/candidato recibe mayor señalamiento sincero de los que compiten, mientras que siendo obligatorias no puede evaluarse si el voto ha sido sincero 0 estratégico, ni tampoco puede determinarse el nivel de intensidad de la preferencia política de cada elector.

33. Paradójicamente, las internas más convocantes para los actores externos suelen ser las que presentan mayor grado de competitividad, pero que también suelen ser las más hostiles y belicosas (King, 1997). 
puede perjudicar la recomposición de los sectores, como también la performance electoral posterior del partido (Key, 1964; Colomer, 2000; Gallo, 2011; Altman, 2012; Freidenberg, 2014). Aquí se considera si las contiendas se desarrollaron de un modo pacífico o conflictivo. ${ }^{34}$

- Grado de retención coalicional ${ }^{35}$ y crecimiento electoral posterior. En las internas compulsivas, el nivel de retención será más alto que en las optativas, al tiempo que habrá un menor crecimiento entre una fase y la otra. La capacidad de retención del partido o alianza depende, por un lado, de que se evite la competencia y la conflictividad, y, por otro, de que exista homogeneidad, solidez coalicional y consistencia ideológica (Lyne, 2005). Para evaluar este ítem, se determinará el porcentaje de individuos que, dentro del conjunto de electores de un partido en los comicios generales, hayan votado previamente por el mismo en las primarias. ${ }^{36}$

- Expectativas de viabilidad. Se buscará averiguar si algún partido/frente dio un batacazo (general o interno) en las primarias. Aquí estableceremos que si el partido tuvo un crecimiento alto posterior y en este ítem logró un valor positivo considerable, ${ }^{37}$ entonces puede hablarse de un efecto batacazo.

34. Al tratarse de una variable inmensurable, se tendrán en cuenta lo anteriormente expuesto y otros estudios de casos complementarios sobre la temática.

35. Es decir, la capacidad del partido para mantener el apoyo, en la elección general, de los votantes de las listas internas derrotadas, sin que se generen defecciones hacia los competidores externos (Reynoso, 20I5; Malamud, 2015).

36. En internas optativas, el parámetro debería ser de alrededor del $50 \%$, mientras que en obligatorias del $100 \%$. Estos números son aleatorios e incluso arbitrarios. Se les utiliza para establecer una diferenciación entre los distintos sistemas de primarias abiertas, presuponiendo que en casos donde la instancia interna tiene el mismo estatus que las generales, lo esperable es que el resultado sea lo más parecido posible en ambas instancias, mientras que en aquellos en que es diferente, la participación sea semejante a la tasa de concurrencia a ese evento electoral. 37. Aquí consideraremos más de diez puntos en internas voluntarias y más de cinco en compulsivas.

\section{6}


- Ordenamiento y racionalización de la oferta partidaria. Se evaluará la cantidad de partidos que quedaron afuera después de esta instancia y su peso electoral, así como el número efectivo de partidos (NEP) electoral ${ }^{38}$ y el número de precandidatos compitiendo, esto para determinar si hubo efectivamente una reducción respecto del promedio histórico establecido desde la recuperación democrática hasta la actualidad. Además de estos elementos, para determinar qué tipo de matriz partidaria ha resultado de tal ordenamiento, habrá que tener en cuenta si los criterios por los cuales este se ha realizado han sido consistentes y de largo plazo.

La Tabla 2 presenta estas variables en cada uno de los casos.

En los dos casos revisados, ha habido una tendencia decreciente a la participación de la ciudadanía en las internas desde la instauración de este sistema. ${ }^{39}$ En Uruguay, los electores de las primarias tienen un perfil diferente a los de la elección general (Buquet y Piñeiro, 2014), lo cual está más acentuado cuanto más reducida es la concurrencia ciudadana en la instancia preliminar (Piñeiro, 2014). En Argentina, el selectorado interno es más parecido al electorado general, en la medida en que las primarias son obligatorias para toda la ciudadanía, con lo cual en ellas se tiende a mantener la misma estructura de incentivos que habitualmente liga a los electores con el partido (Gallo, 2017). Por ello, el voto de las primarias, presuntamente más sincero y genuino, puede ser un voto tan carente de entusiasmo como el de la elección general. En Uruguay, al menos es plausible que un elector que decide ir a votar en

38. El NEP, según la fórmula de Laakso y Taagepera (1979), pondera a los partidos según su tamaño relativo: $\mathrm{N}=\mathrm{I} / \sum \mathrm{Si}^{2}$, donde si es la proporción de votos (NEP electoral). 39. Esto coincide con la evidencia de un distanciamiento cada vez mayor de los electores respecto de las definiciones de los candidatos y de las direcciones partidarias (Caetano y Selios, 2016, p. 10I). 
una instancia optativa sienta cierto entusiasmo por la alternativa por la que se pronuncia. ${ }^{40}$ Por lo tanto, es esperable que el voto sincero en Uruguay sea inferior numéricamente, pero, pese a ello, más intenso que en Argentina. ${ }^{41}$

Tabla 2. Participación ciudadana y voto sincero en Uruguay $y$ Argentina

\begin{tabular}{lcccc} 
Participación & \multicolumn{1}{c}{ 1999 } & 2004 & 2009 & 2014 \\
Uruguay & & & & \\
FA & $17.77 \%$ & $\mathbf{1 8 . 4} \%$ & $17.05 \%$ & $11.52 \%$ \\
PN & $17.04 \%$ & $17.87 \%$ & $\mathbf{1 9 . 0 2 \%}$ & $\mathbf{1 5 . 9 7 \%}$ \\
PC & $\mathbf{2 1 . 7 3 \%}$ & $6.46 \%$ & $4.97 \%$ & $5.35 \%$ \\
Otros & $1.66 \%$ & $0.37 \%$ & $3.76 \%$ & $4.43 \%$ \\
Total & $\mathbf{5 8 . 2 \%}$ & $43.1 \%$ & $44.8 \%$ & $37.27 \%$ \\
Participación Argentina & & 2011 & 2015 \\
FPV & & $\mathbf{3 7 . 2 8} \%$ & $\mathbf{2 7 . 2 \%}$ \\
Unión para el Desarrollo Social (UDESO) & $9.06 \%$ & - \\
Frente Amplio Progresista (FAP) & & $7.55 \%$ & - \\
Cambiemos & & - & $21.18 \%$ \\
UNA & & - & $14.47 \%$ \\
Frente de Izquierda y de los Trabajadores (FIT) & $1.83 \%$ & $2.29 \%$ \\
Otros & $17.44 \%$ & $3.91 \%$ \\
Total & & $\mathbf{8 1 . 4 1 \%}$ & $72.37 \%$ \\
\hline
\end{tabular}

Nota: se considera el porcentaje de electores habilitados que votaron en cada una de las internas. En letras negritas figura la fuerza que concitó mayor participación interna, en particular, y el año en el que hubo mayor participación interna, en general.

Fuente: elaboración propia con base en Atlas Electoral Andy Tow (2015) y Facultad de Ciencias Sociales y Universidad de la República (2015).

40. Claro que existen matices y excepciones, pero por regla general hay una correlación positiva entre no obligatoriedad de la instancia preliminar y entusiasmo por la opción elegida.

4I. Por las razones antes expuestas, según los encuestadores, en 2015 se observaba "decisión de voto, pero no convicción" (Germano, 20I4). Esto es coherente con la disparidad de afección político-partidaria existente en cada uno de los países.

\section{8}


Empero, la escasa participación ciudadana en la interna frenteamplista demuestra, por ejemplo, que aunque Tabaré Vázquez fuera una primera preferencia factiblemente no fuera una preferencia intensa para aquellos que lo señalaron (Bottinelli, 2014), lo cual es acorde con la mencionada presunción de que dentro del universo de votantes frenteamplistas la mayoría serían electores pragmáticos y la minoría creyentes y entusiastas.

En Argentina, en la última elección, el voto sincero no se concentró mayoritariamente en Macri, ${ }^{42}$ de hecho, sólo un tercio de sus electores finales lo había votado en ambas instancias previas. ${ }^{43}$ Esta disociación entre votación sincera y estratégica hacia el triunfador permite corroborar lo expuesto anteriormente respecto a que el actual presidente argentino habría sido vislumbrado por una cantidad considerable de ciudadanos básicamente como una opción de ultima ratio para vencer al kirchnerismo.

42. El voto sincero por Cambiemos fue de $21.18 \%$, pero dentro de ese porcentaje Macri recibió individualmente el $17.22 \%$, según cálculos propios (diez puntos menos que Scioli). Mientras que en Uruguay, del II.52\% de los votos que capturó sinceramente el FA, Vázquez recibió un $9.45 \%$ de voto sincero, y del $15.97 \%$ del PN, Lacalle Pou un $8.68 \%$, también según cálculos propios.

43. De los electores de Macri en el balotaje, el $33.83 \%$ no lo había votado en ninguna ocasión anterior. En el caso de Scioli, ese porcentaje era del $24.18 \%$. Además, de los que señalaron a Macri en el balotaje, un $42.49 \%$ lo había votado individualmente en las PASO; en cambio, a Scioli lo había escogido el $70.8 \%$ de sus votantes posteriores (según cálculos propios). 
Tabla 3. Competitividad en Uruguay y Argentina

\begin{tabular}{lcccc} 
Competitividad Uruguay & 1999 & 2004 & 2009 & 2014 \\
FA & $64.8 \%$ & - & $\mathbf{1 2 . 6 5 \%}$ & $64.13 \%$ \\
PN & $16.02 \%$ & $32.5 \%$ & $\mathbf{1 4 . 3 1 \%}$ & $\mathbf{8 . 9 7 \%}$ \\
PC & $\mathbf{9 \%}$ & $83.2 \%$ & $56.41 \%$ & $47.7 \%$ \\
\hline Competitividad Argentina & 2011 & 2015 \\
FPV & $0 \%$ & $0 \%$ \\
UDESO & $0 \%$ & - \\
FAP & $0 \%$ & - \\
Cambiemos & - & $70.13 \%$ \\
UNA & - & $39.28 \%$ \\
FIT & $0 \%$ & $\mathbf{2 . 5 8 \%}$ \\
\hline
\end{tabular}

Nota: se evalúa la ventaja del ganador interno respecto de su inmediato competidor, en términos porcentuales. En letras negritas figuran las internas competitivas.

Fuente: elaboración propia con base en Atlas Electoral Andy Tow (2015) y Facultad de Ciencias Sociales y Universidad de la República (2015).

En Uruguay, todas las veces en las que los partidos presentaron competencia interna, se produjo una disputa ideológica entre corrientes con divergencias intestinas, ancladas en diferenciaciones políticas e ideológicas de sus sectores constitutivos (Freidenberg y Sánchez, 2002). En Argentina, en cambio, la única fuerza política de carácter ideológico que presentó competencia interna ${ }^{44}$ (el FIT ${ }^{45}$ en 2015) no lo hizo postulando dos opciones alternativas en términos programáticos, sino que se estableció una disputa

44. En Argentina, hasta ahora, los frentes que presentaron competencia interna, $y$ que constituyen una minoría en el total de elecciones celebradas bajo este sistema, han sido asimétricos y desiguales, con lo cual el peso de los sectores eliminados en la primera fase ha sido inferior al del caso uruguayo.

45. Se trató de la única coalición conformada por partidos de la misma tradición ideológica (marxismo-leninismo) que levantaba un programa común, basado en la independencia política de la clase trabajadora (Manifiesto FIT, 20I5). 
de facciones entre los partidos que conformaban el frente ${ }^{46}$ que no le redundó beneficios posteriores.

Por otro lado, puede señalarse incluso que en Uruguay el FA se vio beneficiado cuando no presentó competencia interna. En la única elección en la que hubo un precandidato único a la presidencia (2004), este frente se impuso en primera vuelta. En Argentina, por su parte, desde que se creó el sistema de las PASO, el único candidato de una fuerza política con chances que presentó competencia interna (Cambiemos) terminó consagrado como presidente (Macri). De todos modos, en este último caso, no se trató de una fuerza preexistente que resolvía la apertura de la selección de candidaturas a la ciudadanía común, sino que se trató de una coalición ad hoc, formalizada para este evento electoral, por mera conveniencia y oportunismo circunstancial, ${ }^{47}$ y en la que los socios secundarios anexaron sus listas a la del postulante presidencial que se daba por ganador definido, estableciendo una pseudocompetencia interna entre candidaturas altamente dispares. En efecto, si la entidad que nuclea y aglutina a los subsectores que compiten en la primaria abierta es ficticia, difícilmente la interna abierta puede devenir en una instancia de competencia real.

46. Aunque los partidos de la izquierda mantuvieron la unificación lograda en ocasión de las primeras PASO, de todos modos el campo de la izquierda en su conjunto volvió a estar representado por diversas fuerzas diferenciadas (ver: http://andytow.com/atlas/totalpais).

47. A esto se suma que los partidos asociados en Cambiemos y Unidos por una Nueva Argentina (UNA), y también en el caso de los Progresistas, en algunas provincias eran aliados (Gallo, 20I7), conformando alianzas cruzadas (Clérici, 20I3). 
Tabla 4. Moderación en Uruguay y Argentina

\begin{tabular}{|c|c|c|c|c|}
\hline \multicolumn{2}{|c|}{ Moderación Argentina } & 2011 & & 2015 \\
\hline \multicolumn{2}{|c|}{ FPV } & - & & - \\
\hline \multicolumn{2}{|l|}{ UDESO } & - & & - \\
\hline \multicolumn{2}{|l|}{ FAP } & - & & - \\
\hline \multicolumn{2}{|l|}{ Cambiemos } & - & & Inexistente \\
\hline \multicolumn{2}{|l|}{ UNA } & - & & miconflictiva* \\
\hline \multicolumn{2}{|l|}{ FIT } & - & & Conflictiva \\
\hline \multicolumn{5}{|c|}{$\begin{array}{l}\text { * Aquí Massa y De la Sota optaron por simular artificialmente la } \\
\text { existencia de una interna conflictiva para acaparar atención en el marco } \\
\text { de unas PASO previsibles, lo cual desvirtúa completamente el sentido } \\
\text { originario de la utilización de este tipo de mecanismos. }\end{array}$} \\
\hline $\begin{array}{l}\text { Moderación } \\
\text { Uruguay }\end{array}$ & 1999 & 2004 & 2009 & 2014 \\
\hline FA & Semiconflictiva & - & Conflictiva & Semiconflictiva \\
\hline PN & Conflictiva & Moderada & Moderada & Moderada \\
\hline $\mathrm{PC}$ & Moderada & Inexistente & Inexistente & Inexistente \\
\hline
\end{tabular}

Nota: sólo se evalúan las contiendas en las que haya habido competencia. Se considera "inexistente" cuando la presentación de candidaturas testimoniales impide que se instale la propia interna en el campo electoral. En tipografías negritas figuran las internas moderadas.

Fuente: elaboración propia con base en Colomer (2000), Gallo (2011 y 2016) y Portalfactum (2016).

En Uruguay, de las cinco internas abiertas competidas y competitivas que se celebraron hasta ahora, ${ }^{48}$ tres fueron moderadas y dos fueron conflictivas (Buquet y Chasquetti, 2005; Bottinelli, 2009). En los tres casos de las moderadas, los partidos salieron segundos en la primera vuelta, aunque uno de ellos se impuso en el balotaje, tras la reversión del resultado originario (Gallo, 2011). En general, cuando las primarias son conflictivas, es factible que se complique la resolución ex post, como sucedió en 2009 con la interna del FA, que resultó ser tensa y poco expeditiva (Cardarello y Yaffé, 2011; Gallo y Bartoletti, 2013), o es posible que se 
resienta la unidad partidaria, como sucedió en el PN en 1999 (Freidenberg y Sánchez, 2002).

En Argentina, la única primaria competida y competitiva, la del FIT en 2015, transcurrió de un modo conflictivo. ${ }^{49}$ Además, esta coalición terminó postulando a un candidato inexperto y desconocido (Nicolás del Caño), y tuvo una performance electoral inferior a la obtenida cuando se presentó con listas unificadas (2011 y 2013). ${ }^{50}$

Paradójicamente, la rigidez del sistema argentino, promovida por la inamovilidad de las fórmulas presidenciales, en un principio tuvo la ventaja de hacer que se evitaran muchas de las pugnas interfaccionales. El caso emblemático fue el del FPV ${ }^{51}$ que evitó tener internas conflictivas al precio de no realizarlas, lo que, paralelamente, implicó un contrasentido respecto de las metas de inclusividad y democratización interna pretendidas teóricamente con el sistema de primarias.

El nivel de retención coalicional difiere en función de que las internas sean obligatorias o voluntarias. En los primeros casos, los sectores que compiten, tanto partidarios como subpartidarios, aspiran a que la distribución de los votos internos totales los favorezca por sobre las otras alternativas, mientras que en los segundos se busca no sólo que los ciudadanos los ubiquen entre las opciones elegibles, sino también que estos tomen la decisión de concurrir a votar en esta instancia (Portalfactum, 2016).

Igualmente, en ambos casos, como se mencionó, la capacidad que posee la agrupación para retener a sus votantes

49. Aunque, al tratarse de una fuerza minoritaria, la conflagración no trascendió más allá de los círculos de militantes y simpatizantes estables.

50. Si bien a nivel presidencial en 2015 superó lo obtenido en $201 \mathrm{I}$, a nivel legislativo fue muy pareja. Y además, su performance fue muy inferior a la esperada meses antes, dado el crecimiento que venía teniendo esta coalición partidaria.

$5 \mathrm{I}$. En este partido, históricamente verticalista y poco democrático, en $20 \mathrm{II}$, la presidenta incumbente se autopostuló, y en 2015 , terminó de definir la interna presidencial. 
y crecer posteriormente está ligada a su nivel de solidez y consistencia interna (Tullio, 2015) y a su aptitud para representar intereses societales definidos, mientras que cuando la alianza interpartidaria no aglutina a sus miembros a partir de algún elemento de afinidad política definido, los votos terminan no siendo mecánicamente trasladables de una instancia a la siguiente (Navia y Joignant, 2000), con lo cual hay más oportunidades de que se produzcan fugas posteriores (Tullio, 2015) y es más difícil lograr un crecimiento electoral interfásico (Gallo, 2017).

Tabla 5. Retención y crecimiento interfásico en Uruguay y Argentina

\begin{tabular}{|c|c|c|c|c|}
\hline Retención Uruguay & 1999 & 2004 & 2009 & 2014 \\
\hline FA & $\begin{array}{l}45.76 \%\left(1^{a}\right) / \\
40.13 \%\left(2^{a}\right)\end{array}$ & $40 \%$ & $\begin{array}{c}39.86\left(1^{\mathrm{a}}\right) / \\
44.29 \%\left(2^{\mathrm{a}}\right)\end{array}$ & $\begin{array}{l}26.62 \%\left(1^{a}\right) / \\
24.63 \%\left(2^{a}\right)\end{array}$ \\
\hline PN & $78.92 \%$ & $56 \%$ & $\begin{array}{l}73.38 \%\left(1^{\mathrm{a}}\right) / \\
\mathbf{4 9 . 4 3} \%\left(2^{\mathrm{a}}\right)\end{array}$ & $\begin{array}{l}57.08 \%\left(1^{\mathrm{a}}\right) / \\
\mathbf{4 3 . 7 6} \%\left(2^{\mathrm{a}}\right)\end{array}$ \\
\hline $\mathrm{PC}$ & $\begin{array}{l}68.48 \%\left(1^{\mathrm{a}}\right) / \\
\mathbf{4 1 . 6 1 \%}\left(2^{\mathrm{a}}\right)\end{array}$ & $68 \%$ & $32.76 \%$ & $45.83 \%$ \\
\hline Otros & $34.93 \%$ & $45.18 \%$ & $33.01 \%$ & $54.75 \%$ \\
\hline Retención Argentina & & 2011 & & 2015 \\
\hline FPV & & $90.71 \%$ & & $94.19 \%$ \\
\hline UDESO & & $107.01 \%$ & & - \\
\hline FAP & & $59.16 \% *$ & & - \\
\hline Cambiemos & & - & & $79.12 \%$ \\
\hline UNA & & - & & $91.22 \%$ \\
\hline FIT & & $104.74 \%$ & & $04.74 \%$ \\
\hline
\end{tabular}

* Esta fuerza claramente dio un batacazo general que replicó en la instancia siguiente, habiendo obtenido $65.75 \%$ más de votos en la elección general que en las PASO.

Nota: se considera, sobre el conjunto de votantes del partido en la elección general, el porcentaje de aquellos que votaron por el mismo previamente en interna. En tipografías negritas figuran los partidos/ frentes que tuvieron mayor retención o crecimiento interfásico, el cual está representado por los valores más bajos.

Fuente: elaboración propia con base en Atlas Electoral Andy Tow (2015) y Facultad de Ciencias Sociales y Universidad de la República (2015). 
Cabe mencionar dos casos curiosos de partidos que formaron parte de una coalición de diferente naturaleza, pero con puntos en común: la Unión Cívica Radical (UCR), en Argentina, que participó en la formación de Cambiemos, quedando completamente diluida dentro del mismo, y el Partido Colorado (PC), en Uruguay, que compitiendo de modo unitario fue un aliado coyuntural de su antiguo rival histórico, el Partido Nacional (PN), desde los años noventa. Ambos partidos tuvieron inconvenientes a la hora de retener a sus votantes estables: ${ }^{52}$ la UCR ni siquiera logró que sus adherentes se volcaran masivamente por la nueva alianza, e incluso hubo una resistencia muy grande a aceptar el acuerdo por parte de un sector del partido. En el caso del $\mathrm{PC}$, una porción de simpatizantes no intensos de esta fuerza ejerció un voto estratégico, pronunciándose directamente por Lacalle $\mathrm{Pou}^{53}$ porque este tenía más chances de imponerse sobre el FA.

En cuanto a las fuerzas que resultaron finalmente ganadoras en la última elección, en ambos países estas fueron incrementando su apoyo a lo largo del ciclo eleccionario: ${ }^{54} \mathrm{en}$ Uruguay, como producto de la existencia de internas optati-

52. Ambos son partidos centenarios, de perfil socialdemócrata, con arraigo en los grandes centros urbanos. En los dos casos, el corrimiento hacia posiciones conservadoras les ocasionó el abandono de una porción significativa de su electorado estable, al cual no han podido volver a atraer. El electorado progresista de ambas fuerzas históricas decidió volcarse por alguna de las opciones ideológicamente afines con más oportunidades, con lo cual su apoyo se redujo a un núcleo duro históricamente fiel y disciplinado.

53. El I5\% del total de electores uruguayos se ubicaría en una zona denominada frontera, capaz de apoyar a un colorado o a un blanco (El Observador, 20I4).

54. En Uruguay, el apoyo ciudadano al FA fue cayendo desde el comienzo del año 2014 , y luego inició un proceso de recuperación a lo largo del ciclo eleccionario. En Argentina, hasta marzo de 2015, el promedio de lo que le adjudicaban las encuestadoras a Macri no superaba el $22 \%$, hasta las PASO no alcanzaba el $30 \%$, y después de esa instancia alcanzaba el tercio del apoyo. En los dos casos, de cara a la primera vuelta, las encuestas presagiaron que el candidato finalmente ganador obtendría alrededor de cinco o seis puntos menos de los que sacó, lo cual da lugar a inferir un voto sin entusiasmo, e incluso un voto vergonzante hacia esa opción partidaria. 
vas y de una participación decreciente, el FA experimentó una progresiva ampliación de la brecha entre el voto más duro y genuino y el más estratégico y desapegado. En la Argentina, la existencia de primarias obligatorias y de una coalición asimétrica (Cambiemos) cuyas listas secundarias tenían una escasa gravitación electoral facilitó la conservación de apoyos entre las fases. De todos modos, el triunfo final de esta fuerza se debió no tanto a los votantes que pudo retener de fase en fase, sino al apoyo último de ciudadanos que no la habían señalado en ninguna de las ocasiones previas, y que factiblemente la vislumbraron como mal menor frente a la coalición gubernamental kirchnerista (Gallo, 2017).

Tabla 6. Expectativas de viabilidad en Uruguay y Argentina

\begin{tabular}{lrrrc} 
Expectativas Uruguay & 1999 & 2004 & 2009 & 2014 \\
FA & 8.53 & 7.65 & 6.74 & $\mathbf{1 4 . 8}$ \\
PN & -7.56 & -6.36 & -16.9 & -16.04 \\
PC & -5.41 & -4.39 & 5.01 & -2.75 \\
Otros & 1.82 & 1.86 & 2.38 & -3.98 \\
Expectativas Argentina & 2011 & 2015 \\
FPV & 3.87 & -1.59 \\
UDESO & -1.06 & - \\
FAP & $\mathbf{6 . 6 3}$ & \multicolumn{2}{c}{-} \\
Cambiemos & - & 4.04 \\
UNA & - & 0.82 \\
FIT & -0.16 & -0.96 \\
\hline
\end{tabular}

Nota: se trata del porcentaje diferencial de lo obtenido por un partido/frente entre internas abiertas y elecciones generales. En tipografías negritas figura la fuerza que mayor diferencia obtuvo en un caso y en el otro.

Fuente: elaboración propia con base en Atlas Electoral Andy Tow (2015) y Facultad de Ciencias Sociales y Universidad de la República (2015).

Como se dijo, en las primarias puede producirse un batacazo, que, a su vez, puede ser interno o general, si los números obtenidos electoralmente difieren considerablemente de

\section{6}


las expectativas previas. En Argentina, en las elecciones de 2011, hubo un batacazo general, efectuado por el FAP ${ }^{55}$-la coalición que constituyó la novedad o revelación en las PASO de ese año- ${ }^{56}$ que luego pudo replicarse en la primera vuelta electoral, y en los comicios de 2015 se produjo un batacazo interno en el FIT con el triunfo inesperado de Del Caño. ${ }^{57}$

En Uruguay, en 2009, el PN dio un batacazo general, siendo el partido más votado en las internas, lo que no se repitió luego en las generales. En 2014, al igual que 2009, este partido fue el que recibió más votos en la jornada de las primarias, lo cual, de algún modo, era esperable, ya que era el único cuya interna presentaba competencia real, aunque el candidato singularmente más votado resultó ser, esta vez, el frenteamplista Tabaré Vázquez. A la vez, dado el antecedente de 2009, cuando el partido más apoyado en las internas salió segundo en las generales y perdió en el balotaje, dejó de considerase el dato de la mayor preferencia interna como indicativo de una predilección superior posterior (Portalfactum, 2016). Igualmente, ese año, el PN experimentó un batacazo interno ${ }^{58}$ con la victoria de Lacalle Pou, dando lugar a la configuración de un escenario de cara a octubre que tenía a ese partido y a su candidato mucho mejor posicionados de lo que realmente estuvieron después.

55. El FAP se disolvió al poco tiempo, sin siquiera llegar a presentarse como tal en las elecciones siguientes.

56. En las elecciones legislativas de 2013 , se produjo algo semejante con el FR. Ambos obtuvieron más bancas de lo que hubieran sacado de haberse definido en las primarias. Cabe resaltar que ninguno de ellos había presentado competencia interna. 57. Todas las encuestadoras daban como ganador de esa interna al histórico líder del Partido Obrero (PO), Jorge Altamira (ver: http://observatorio.lapoliticaonline. com/\#paso).

58. Si bien el triunfo del candidato Jorge Batlle en 1999 podría considerarse también un batacazo interno, aquí se le ha excluido de esa categoría por dos razones básicas: por un lado, porque para el final de la campaña había paridad e incluso ciertos analistas le deban una leve ventaja (González, 1999), y por otro, porque ese triunfo fue sumamente objetado, al sospecharse de haber recibido votos opositores (Gallo, 20I I). 
Vemos, pues, que en ambos países los batacazos internos, sustentados en liderazgos de popularidad de postulantes jóvenes ${ }^{59}$ que derrotaron a dirigentes partidarios históricos, no se replicaron en la elección general.

Es decir, hasta ahora, los candidatos que han dado un batacazo al interior de sus partidos no han logrado que ese efecto se traslade a nivel nacional en la elección siguiente, mientras que los batacazos generales que se replicaron en la instancia posterior provinieron de fuerzas emergentes ${ }^{60}$ que no presentaron competencia interna. Si bien son pocos los casos que se analizan como para sacar conclusiones al respecto, podría estudiarse la posible correlación entre ausencia de competencia interna y buen desempeño general de la formación, ${ }^{61}$ entendiendo que la presentación unitaria pueda ser bien evaluada por la ciudadanía (suposición que se contrapone al argumento de que la competencia favorece el cumplimiento de los objetivos teóricos de las internas abiertas). A su vez, si los únicos batacazos que se replican son los generales $-\mathrm{y}$ en fuerzas sin competencia-, las primarias pierden efecto informativo y legitimador, y se transforman directamente en una primera vuelta adelantada (Gallo, 2017).

Como se mencionó, las internas/primarias abiertas como regla electoral pueden producir efectos mecánicos, como la eliminación de actores que no superen el piso o umbral establecido, y también psicológicos, como la conformación de alianzas entre fuerzas afines para poder competir en ellas.

59. Luis Lacalle Pou tenía cuarenta y un años, y Nicolás del Caño treinta y cinco. 60. Podría argumentarse que el FPV concitó ese efecto legitimante, que le permitió imponerse en primera vuelta. No obstante, aquí se prefiere referir con el término batacazo a la obtención de un resultado inesperado.

6I. Muchos adherentes partidarios intensos no se sienten estimulados por los escenarios de primarias competidas y consideran que la gran batalla son las elecciones nacionales, momento en el que hacen prevalecer su identidad colectiva suprapartidaria por sobre la identidad subpartidaria sectorial, presentándose unidos ante los demás (Gallo, 20II). 
Como se observa, ni en Uruguay ni en Argentina hubo, efectivamente, una disminución del número de contendientes, al tiempo que la variación en el NEP ha sigo poco relevante en términos comparativos. En la medida en que con este sistema se desdoblan las instancias electorales, lo que se redujo en cantidad de candidatos postulados, respecto del promedio histórico, se aumentó en número de precandidatos compitiendo. Por lo tanto, si se considera al ciclo eleccionario como un todo, debe concluirse que la tendencia ha sido al aumento y no a la reducción de los participantes.

Además, en ninguno de los dos países, la exclusión de competidores tras las internas resultó significativa, ni en términos numéricos ni en términos de peso electoral de las fuerzas eliminadas. Por lo tanto, la incorporación de un umbral de exclusión no ha tenido efectos sobre el ordenamiento de la oferta partidaria. En Uruguay, por ejemplo, la estabilidad del sistema de partidos no tiene relación con la existencia de un piso -que además, al ser tan bajo, es incapaz de producir alteración alguna-, sino con el incuestionable protagonismo que los tres partidos principales tienen en la definición electoral de los ciudadanos, lo que ha impedido desplazar la oferta hacia opciones ajenas a ellos (Vairo y Rodríguez, 2016).

A su vez, como se ha expuesto reiteradamente, lo fundamental no es que se ordene o no la oferta partidaria, sino establecer en función de qué criterio se produce tal ordenación. En Uruguay, como se dijo, el sufragio es muy partidizado y la ciudadanía vota muy firmemente por los partidos (Bottinelli, 2009), al tiempo que estos se organizan en función de dos bloques discernibles en lo ideológico y en su alineación (o no) con el Gobierno. En Argentina, hasta ahora, la presión psicológica ejercida por el umbral legal ha derivado en que se conformen alianzas cruzadas y coyunturales, lo cual, sumado a la existencia de candidatos ideológicamente fluctuantes y de alineamientos variables, 
ha dificultado que se establezca un criterio relevante y sustantivo (partidario, ideológico, programático, etc.) conforme al cual se efectúe la racionalización y ordenación del sistema partidario (Gallo, 2017).

Tabla 7. Ordenamiento de la oferta partidaria en Uruguay y Argentina

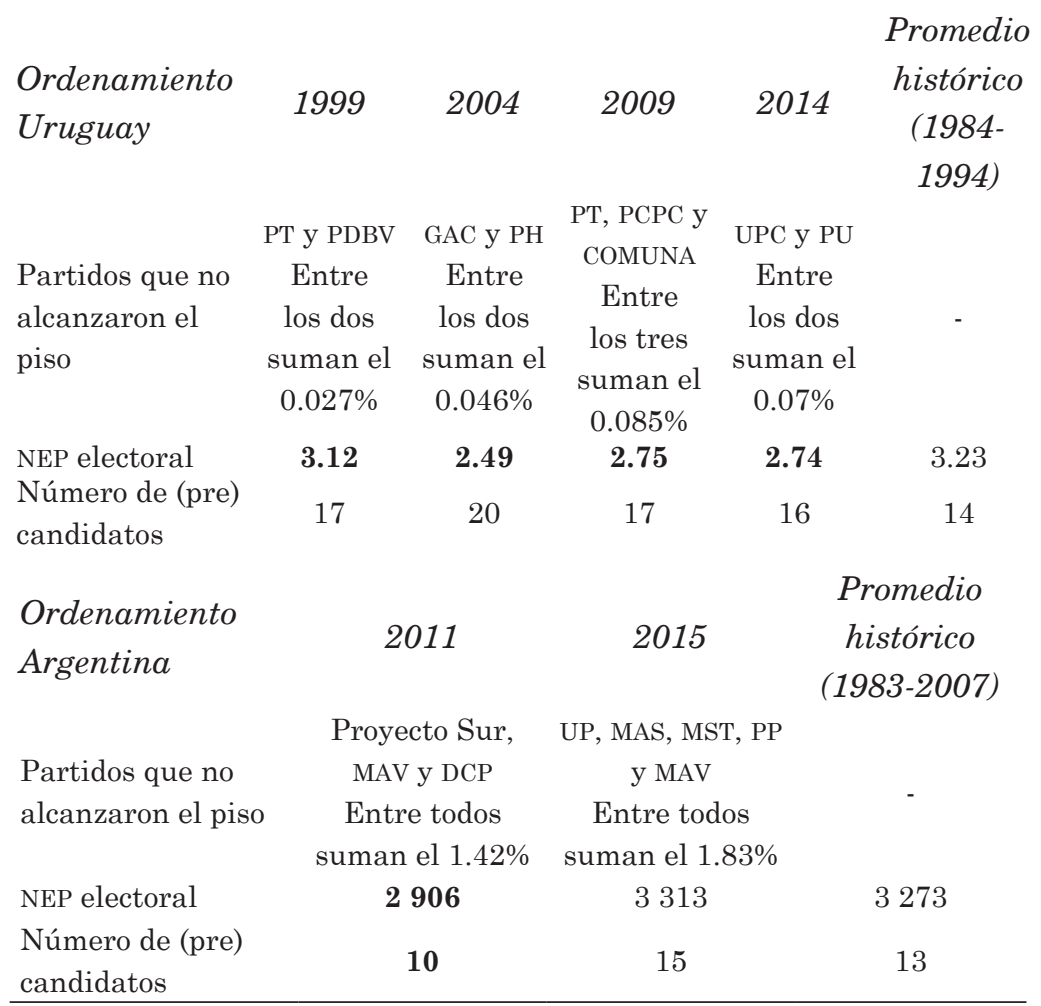

Nota: se consideran los partidos que no alcanzaron el piso (de quinientos votos en Uruguay y del $1.5 \%$ de los votos válidamente emitidos en Argentina), y el peso electoral que tenían en su conjunto. También se tienen en cuenta el NEP electoral y la cantidad de precandidatos presidenciales totales (sumando a todos los provenientes de todas las fuerzas que participaron en las internas). En la última columna figura el promedio histórico desde la recuperación democrática hasta el cambio en la legislación, tanto del NEP como del número de candidatos presidenciales (no precandidatos, ya que no existía esa opción). En tipografías negritas

\section{0}


figuran el NEP inferior al promedio histórico y el número de precandidatos presidenciales inferiores al promedio histórico de los mismos.

Fuente: elaboración y cálculos propios sobre la base de_Atlas Electoral Andy Tow (2015), Facultad de Ciencias Sociales y Universidad de la República (2015), Corte Electoral República Oriental del Uruguay (2015) y Ministerio del Interior, Obras Públicas y Vivienda (2015).

\section{Conclusiones}

En este trabajo, se evaluó la utilización de internas/primarias abiertas, simultáneas y obligatorias en Argentina y Uruguay, los dos países de América Latina en los que estas elecciones poseen regulación oficial. Se estimó relevante el estudio de este mecanismo, tanto desde el punto de vista académico como en lo referente a su aplicación fáctica a pocos años de su incorporación formal.

Mantenemos una posición crítica respecto de los presuntos beneficios de este sistema como instrumento selectivo, los cuales apuntaban al mejoramiento del funcionamiento partidario, tanto en lo interno como en lo externo. A lo largo del trabajo pudimos observar que es difícil compatibilizar todos los objetivos que teóricamente acarrearía este sistema (participación, voto sincero, competitividad, moderación, crecimiento electoral) en todos los partidos existentes y en un mismo evento eleccionario -en el que, a su vez, se ordenara y simplificara la oferta partidaria-. En efecto, hasta ahora no puede atribuírsele una ventaja específica a la presentación de competencia interna, ya que los partidos que celebraron primarias competitivas no tuvieron mejores resultados respecto a antes de usarlas, tampoco respecto de sus congéneres, ni, se puede especular, de los que hubieran tenido postulando un solo candidato en la contienda.

Cabe señalar que ciertas características del caso argentino, relativas tanto a sus rasgos previos como a elementos específicos incorporados con la legislación, podrían agravar 
el incumplimiento de los mencionados beneficios, generando un sistema que no sea antecedido por una regla electoral que favorezca el sufragio presidencial intrapartidario (como la Ley de Lemas, en Uruguay), que no haya congruencia interna en los actores partidarios ni paridad entre elementos subpartidarios participantes, y que no exista la posibilidad de incluir a los derrotados internos en las fórmulas definitivas.

La corta experiencia en la utilización de esta metodología nos permite observar que hasta ahora no ha habido una tendencia al incremento de la participación e interés ciudadano en los eventos selectivos, y que el voto más sincero y entusiasta -en caso de que haya existido en una porción significativa- no necesariamente se ha concentrado en los ganadores.

En relación con la competitividad interna, esta sólo tiene sentido cuando en una fuerza política existen al menos dos candidatos competitivos diferenciados. A su vez, en coaliciones asimétricas y oportunistas, en las cuales los partidos no estén unidos conforme a criterios de afinidad ideológicoprogramática, sino por cuestiones de mera conveniencia, los competidores no entrarán a la contienda en igualdad de condiciones y, una vez finalizada la competencia, difícilmente se logrará que los derrotados busquen preservar la presencia de la entidad suprapartidaria.

Con respecto a las variaciones entre los números de las primarias y los de la primera vuelta en función de las expectativas generadas previamente, observamos que las internas no han sido predictores efectivos de los resultados en la elección general, tanto entre los partidos como dentro de ellos (Buquet y Piñeiro, 2011; Piñeiro, 2014), con lo cual inferimos también que la existencia de un batacazo preliminar no es un indicador concluyente sobre comportamientos electorales futuros.

Por último, el sistema de partidos uruguayo se mantuvo estable por razones que no se ligan directamente al cambio 
de reglas electorales, sino que se vinculan con las características partidarias previas y con la vocación participativa de la ciudadanía en ese país.

Partiendo de una situación diferente, en Argentina, hasta ahora, estas reglas no han promovido la existencia de una matriz partidaria más organizada, compuesta por partidos fuertes y estables. Por el contrario, hasta el momento, se ha tendido a fomentar la presencia de coaliciones políticas coyunturales, informalmente estructuradas y programáticamente difusas, lo cual también ha influido sobre el nivel de retención y crecimiento de las coaliciones, la mayoría de las cuales se han desintegrado antes de los comicios inmediatamente posteriores. Sucede que el sistema de PASO presupone que el criterio partidario sea el principal elemento configurador del voto ciudadano; pero dado el carácter transitorio que la legislación le otorga a las alianzas y el tipo de competencia personalizada que tiende a establecerse en las primarias, el partido como tal queda desdibujado, en detrimento de las figuras individuales de los candidatos. ${ }^{62}$

Finalizamos apuntando que las conclusiones de este trabajo son acotadas y de alcance limitado, ya que hemos analizado un número muy reducido de casos en los que se han celebrado aún pocas elecciones primarias (especialmente en Argentina, donde el uso de este sistema no ha estado suficientemente generalizado hasta el momento como para hablar de tendencias establecidas). Sin embargo, a partir del análisis de las variables aquí elaboradas, que contemplan el cumplimiento de los objetivos propuestos teóricamente en este sistema, sentamos las bases para ir realizando una investigación más amplia, buscando llegar a conclusiones más contundentes en la medida en que sigan sucediéndose elecciones bajo este dispositivo eleccionario.

62. Si bien la coalición gubernamental Cambiemos subsiste y fue ratificada en los comicios de medio término de 2017 , ha sido cooptada prácticamente por su partido central (el PRO), dejando a la histórica UCR al borde de la extinción definitiva. 
Alcántara Sáez, M. (2002). "Experimentos de democracia interna. Las primarias de partidos en América Latina". Kellogg Institute, Working Paper, (293). Recuperado de: http://www.nd.edu/ kellogg/WPS/293.pdf

Alcántara Sáez, M.,y Freidenberg, F. (Coord.) (2003).Partidos políticos de América Latina. Cono Sur. México: FCE.

Altman, D. (2004). "Political Recruitment and Candidate Selection in Chile (1990-2003):The Executive Branch". Trabajo presentado en Symposium on Pathways to Power: Political Recruitment and Democracy in Latin America. Wake Forest University, Winston-Salem.

Altman, D. (2012). "Universal Party Primaries and General Election Outcomes: The Case of Uruguay (1999-2009)”. Parliamentary Affairs, 66(4), I-22.

Anduiza, E., y Bosch, A. (2004). Comportamiento político y electoral. Barcelona:Ariel.

Ansolabehere, S., Snyder, J., y Stewart, C. (2000). The Effects of Party and Preferences on Congressional Roll Call Voting. Massachusetts: Institute of Technology.

Atkenson, L. R. (1998). "Divisive Primaries and General Election Outcomes:Another Look at Presidential Campaigns”. American Journal of Political Science, 42(I), 256-27I. Atlas Electoral AndyTow (2015).“Elecciones presidenciales $20 \mathrm{I} \mathrm{I}$ y elecciones presidenciales 2015”. Recuperado de: http:// www.andytow.com/blog/suscripcion-al-atlas-electoral/

Benoit, K. (2006). "Duverger's law and the study of electoral systems". French Politics, 4(I), 69-83.

Boix, C. (1998). Political Parties, Growth and Equality. Conservative and Social Democratic Strategies in the World Economy. Londres: Cambridge University Press.

Bottinelli, O. (2009). Algo más complicado que internas. Recuperado de: http://www.aucip.org.uy/docs/ oscar2009_03_29.pdf 
Bottinelli, O. (20|4). "Balance de un complicado año elecBibliografía toral”. Factum. Recuperado de: http://www.factum.uy/ analisis/20I4/ana I4I226.php.

Buquet, D., y Chasquetti, D. (2005).“Elecciones Uruguay 2004. Descifrando el cambio”. Revista de ciencia política, 25(2), I43-I52.

Buquet, D., y Piñeiro, R. (20I I). Participation and Effects of Primary Elections in Uruguay. Sao Paulo: IPSA-ECPR.

Buquet, D.,y Piñeiro, R. (2014)."La consolidación de un nuevo sistema de partidos en Uruguay”. Debates, 5(2), I27-I 48. Caetano, G., y Selios, L. (2016). “El ciclo electoral de 2014 en Uruguay ¿Todo igual?”, en F. Mayorga (Comp.), Elecciones y legitimidad democrática en América Latina (pp. 95-I38). Buenos Aires: CLACSO.

Caillabet, C. (20I4). Constanza. El desafio. Montevideo:Trilce. Cardarello, A., y Yaffe,J. (20II)."Crónica de una victoria anunciada”, en D. Buquet, y N. Johnson (Coords.), Del cambio a la continuidad. Ciclo electoral 2009-2010 en el Uruguay (pp. 23-43). Montevideo: Fin de Siglo.

Carey, J., y Polga Hecimovich, J. (2004). Primary Elections and candidate strenght in Latin America. Recuperado de: http:// www.darmouth.edu/jcarey

Caruncho, L. (20I4).“'De la maquinaria partidaria a la industria electoral. Continuidades e incentivos institucionales en la Argentina: del radicalismo al kirchnerismo". Revista SAAP, $8(2), 491-519$.

Cheresky, I.(1999).“Elecciones internas de laAlianza:aparatos partidarios y ciudadanía independiente". Instituto Gino Germani, (I3), I-23.

CIFRA (3I de octubre de 20I4). Recuperado de: http://www. cifra.com.uy/

Clérici, P. (20I3). “Alianzas cruzadas en Argentina”. Ciencia Política, (16), 8-33.

Colomer,J.(2000).“Las elecciones primarias presidenciales en América Latina y sus consecuencias políticas”. Ponencia 
presentada en el XXX Congreso de la Asociación de Estudios Latinoamericanos (LASA). Miami.

Colomer, J. (2004). Cómo votamos. Los sistemas electorales del mundo: pasado, presente y futuro. Barcelona: Gedisa.

Corte Electoral República Oriental del Uruguay (2015). Elecciones nacionales 20/4. Recuperado de: http://www. corteelectoral.gub.uy/gxpsites/

Cox, G. (1997). La coordinación estratégica de los sistemas electorales del mundo. Barcelona: Gedisa.

Denver, D., y Hands, G. (1985). "Marginality and Turnout in General Elections". British Journal of Political Science, I5(99), 38I-398.

El Estadista (20I5). "Panel 4: las tendencias electorales. Las encuestas sobre intención de voto" [vídeo disponible en línea]. Recuperado de: https://www.youtube.com/ watch? $v=i B z t W 7 G s y J w \& t=12 \mathrm{~s}$

El Observador (22 de junio de 20I4). "Voto en gallinero ajeno". Recuperado de: http://www.elobservador.com. uy/voto-gallinero-ajeno-n28I580

El Observador TV (27 de octubre de 2014). “Adolfo Garcé en El ObservadorTV tras la primera vuelta" [video disponible en línea]. Recuperado de: https://www.youtube. $\mathrm{com} /$ watch? $v=D C j 6$ YYuIDI\&t $=15 \mathrm{~s}$

Epstein, L. (1980). Political parties in Western Democracies. New Brunswick:Transaction Books.

Equipos Mori (3I de octubre de 2014). Recuperado de: http://www.equipos.com.uy/

Escolar, M. (20I I)." "Discusión sobre la Nueva Ley Electoral”. Trabajo presentado en Seminario sobre reforma política en la Argentina. Asociación política Casa Generación Política Sur, Buenos Aires, Argentina.

Factum (3I de octubre de 20I4). Recuperado de: http:// www.factum.uy/index.php

Facultad de Ciencias Sociales, y Universidad de la República (2015). Elecciones presidenciales 1980-2004. Recuperado 
de:http://www.fcs.edu.uy/pri/archivos/Elecciones_PreBibliografía sidenciales/blanco_anulados_1980-2004.xls

Freidenberg, F. (2003). Selección de candidatos y democracia interna en los partidos de América Latina. Lima: International IDEA.

Freidenberg, F.(2014).“'La reina de las reformas. Las elecciones internas a las candidaturas presidenciales en América Latina”, en F. Freidenberg, y B. Muñoz (Eds.), Las reformas políticas a las organizaciones de partidos (Pp. 3I-9I). México: INE, TEPJF, OEA, Instituto de Iberoamérica, SAAP.

Freidenberg, F., y Sánchez, L. F. (2002). “¿Cómo se elige un candidato a presidente? Reglas y prácticas en los partidos políticos de América Latina". Revista de estudios políticos, (I I8), 32I-36I.

Gallagher, M., y Marsh, M. (Ed.) (1988). Candidate Selection in Comparative Perspective. The Secret Garden of Politics. Londres: Sage Publications.

Gallo, A. (20I I). Internas abiertas y representatividad democrática: análisis y comparación de los casos pioneros en América Latina. Buenos Aires: Prometeo.

Gallo, A. (20I7). "Un doble P.A.S.O. electoral. Análisis del debut del sistema de primarias abiertas y de la doble vuelta electoral en las elecciones presidenciales argentinas de 20I5”. Revista Studia Politicae, (4I), 40-87.

Gallo, A., y Bartoletti, J. (20I3). "FA y FPV/PJ. organización intrapartidaria y giro a la izquierda en América del Sur”, en A. Fernández (Comp.), Rasgos y perspectivas de la nueva izquierda de América del Sur (pp. 8I-I20). Rosario: Homo Sapiens.

Garcé, A. (2010). “Uruguay 2009. De Tabaré Vázquez a José Mujica”. Revista de ciencia política, 30(2), 499-535.

Garcé, A. (16 de noviembre de 20 I4)."Mientras cae el telón”. El Observador. Recuperado de: http://www.elobservador. com.uy/columna-garce-mientras-cae-el-telon-n292857 
Germano, J. (20I4). "Hay intersecciones de votantes muy grandes entre Scioli, Macri y Massa”. El Estadista. Recuperado de: http://elestadista.com.ar/?p=5292

González, L. E. (1999).“'Las internas partidarias”. Cifra. Recuperado de: http://www.cifra.com.uy/columnas99.htm

Harmel, R., y Janda, K. (1982). Parties and their envoirments. Limits to reforms? Nueva York: Longmans.

Haro, R. (2002).“Elecciones primarias abiertas. Aportes para una mayor democratización del sistema político”, en R. Haro (Comp.), Constitución, poder y control (pp. 55-77). México: Universidad Nacional Autónoma de México.

Interconsult (3I de octubre de 20I4). Recuperado de:http:// interconsult.com.uy/?page_id $=685$

iProfesional (09 de marzo de 20I5).“Zuleta Puceiro:'Veo una elección polarizada entre Macri y Daniel Scioli’'. Recuperado de: http://www.iprofesional.com/notas/207635Zuleta-Puceiro

Jones, M., y Hwang, W. (2007). "Jefes de provinciales de partido, piedra angular del congreso argentino", en S. Emiliozzi, M. Pecheny, y M. Unzué (Comps.), La dinámica de la democracia: representación, instituciones y ciudadanía en Argentina (pp. 217-247). Buenos Aires: Prometeo.

Kemahlioglu, O.,Weitz-Shapiro, R., e Hirano, S. (2009).“Why Primaries in Latin American Presidential Elections?" The Journal of Politics, 7 I ( I), 339-352.

Key, V. O. (1964). Politics, Parties and Pressure Group. Nueva York: Cromwell Company.

King, G. (1997). A solution to the ecological inference problem. Princeton: Princeton University Press.

Kollman, P. (09 de octubre de 20 I I)."El horizonte cercano”. Página I 2. Recuperado de: http://www.pagina I 2.com.ar/ diario/elpais/ I- I 78548-20 I I- I0-09.html

Lanzaro, J. (200I). "Democracia presidencial y alternativas pluralistas. El caso uruguayo en perspectiva comparada", en I. Cheresky, e I. Pousadela (Comp.), Política e institu- 
ciones en las nuevas democracias latinoamericanas (pp. |89-23|). Buenos Aires: Paidós.

Lyne, M. (2005). "Parties as Programmatic agents. A test of institutional theory in Brazil". Party Politics, I I (2), I 93-2 I6.

Malamud, A. (24 de junio de 2015). "Votando con el enemigo”. El Estadista. Recuperado de: http://elestadista. com.ar/?p=7336.

Manifiesto FIT (20I5). Recuperado de: http://www.laizquierdadiario.com/elecciones20 I5/declaracion-programaticafit-caba-20I5/

Ministerio del Interior, Obras Públicas y Vivienda (2015). Elecciones 2015. Recuperado de: http://www.elecciones. gob.arl.

Muñoz, R. (2003). "El proceso circular de las internas abiertas, obligatorias y simultáneas”, en R. Muñoz (Comp.), Crisis de representación y reforma política (pp. |37-I7I). Río Cuarto: CEPRI.

Navia, P., y Joignant,A. (2000)."'Las elecciones presidenciales de 1999: la participación electoral y el nuevo votante chileno", en F. Rojas (Ed.), Chile 1999-2000. Nuevo Gobierno: desafios de la reconciliación (Pp. I-22). Santiago: FLACSO.

Núñez Castellano, R. (20I4). "Democracia, elecciones y cambio político en Uruguay”. Relatoría del seminario Democracia, cambio político y elecciones en América Latina. Centro de Estudios Políticos y Constitucionales, Instituto de Estudios Latinoamericanos, Universidad de Alcalá, España. Recuperado de: http://www.cepc.gob.es/docs/ default-source/nuevas-iniciativas/relator\%C3\%ADa-delseminario-uruguay.pdf?sfvrsn $=2$

Observatorio Electoral Argentino (2015). ¿A dónde fueron los votos entre la primera y segunda vuelta electoral presidencial? Recuperado de: http://oear.cippec.org/novedades/ ballotage-20 I 5-mira-adonde-fueron-los-votos-de-laprimer-a-la-segunda-vuelta-electoral/ 
Page, M. (20I6). "Breve historia de las PASO”. Observatorio Electoral Argentino. Recuperado de: http://oear.cippec. org/novedades/breve-historia-de-las-paso/

Passarello Luna, H. (2009). “Abal Medina: los partidos pequeños saldrán fortalecidos”. Argentina Elections. Recuperado de: http://www.argentinaelections.com/2009/I I/abalmedina-los-partidos-pequenos-saldran-fortalecidos/

Piñeiro, R. (2014)."Factores de mediano y largo plazo para el análisis del proceso electoral de 2014 en Uruguay".Trabajo presentado en el Ciclo monitor electoral: después de las internas: la campaña hacia las elecciones nacionales de octubre. Konrad Adenauer Stiftung, Universidad Católica del Uruguay, Montevideo. Recuperado de: http://www. kas.de/wf/doc/ I32 I 2- I442-4-30.pdf

Portalfactum (2016). "Lo más importante de las elecciones del Frente Amplio es la cantidad de votantes" [video disponible en línea]. Recuperado de: https://www.youtube.com/watch?v=LLhHriL9Q4E

Prats, M. (20I2). “Contradiciendo los pronósticos. ¡No hay descentralización ni inclusión que valga! La selección de candidatos en los partidos políticos de Argentina". América Latina hoy, 62, I03-130.

Rahat, G.,y Hazan, R. (200I). "Candidate Selection Methods: An Analytical Framework". Party Politics, 7(3), 47-7I.

Reynoso,D.(20I5).“La carrera de fondo en el kirchnerismo”. La Voz. Recuperado de: http://www.lavoz.com.ar/opinion/la-carrera-de-fondo-en-el-kirchnerismo

Straface, F., y Page, M. (20I0).“Reforma política 2009: ¿cómo impacta en el sistema de partidos y en los electores?". Documento de políticas públicas, (7I), s/p.

Tejerizo,J.(2009).“Astarita: el proyecto atiende una cuestión central como es la excesiva fragmentación de nuestro sistema partidario". Argentina Elections. Recuperado de: http://www.argentinaelections.com/2009//2/astarita- 
el-proyecto-atiende-una-cuestion-central-como-es-laBibliografía excesiva-fragmentacion-de-nuestro-sistema-partidario/ Tullio, A. (20I0). "Los partidos políticos como reaseguro de estabilidad y legitimidad democrática. La reforma política en la Argentina actual". Ponencia presentada en el XV Congreso internacional del CLAD sobre la reforma del Estado y de la administración pública. Santo Domingo, Republica Dominicana.

Tullio,A. (20I5). El voto de las PASO se reconfigurará sólo si la alianza es muy heterogénea. Recuperado de: http://www. qmundanos.com.ar/nota/20I5-2-16

Vairo, D., y Rodríguez, J. (2016). “Comportamiento electoral en el Uruguay. La victoria de Tabaré Vázquez en las elecciones presidenciales de 20I4". Portal de periódicos UFSC. Recuperado de: https://periodicos.ufsc.brlindex.php/ emtese/article/download/...20 /6v/3n2p/4/33072

Weber, M. (1922). Economía y sociedad. México: FCE.

Yaffé,J. (2005). Al centro y adentro. La renovación de la izquierda y el triunfo del Frente Amplio en Uruguay. Montevideo: Linardi y Risso.

Zelaznik, J. (20I5). “Primarias abiertas 20I5”. Ponencia presentada en Resultados y escenarios después de las PASO. Universidad Di Tella, Buenos Aires, Argentina.

Zovatto, D. (200 I).“'La reforma político-electoral en América Latina: evolución, situación actual y tendencias; 19782000". CLAD reforma y democracia, (2I), s/p. 